\title{
La comunicación en tiempos de crisis
}




\title{
Medio siglo de agresiones a periodistas. Síntesis estadística de asesinatos y desapariciones en América Latina (1970-2015)
}

\author{
Bernardo Díaz Nosty \\ (Universidad de Málaga, España)
}

Recibido: $31 / 8 / 2015$

Aprobado: 22/9/2015

\begin{abstract}
Resumen. Desde 1970, hay constancia en América Latina de más de mil periodistas asesinados o desaparecidos forzados, por razones que han variado a lo largo del tiempo. Desde las medidas represivas propias del terrorismo de Estado, en los años de las dictaduras militares, a la conjunción actual de circunstancias -corrupción política y crimen organizado- que obstruyen la libertad de prensa mediante actividades propias, en ocasiones, de Estados fallidos. La impunidad de los atentados contra los medios y los periodistas aparecen como un incentivo para quienes recurren al silencio de la muerte como solución autoritaria frente a las libertades públicas de la democracia. La geografía del crimen se centra hoy en la franja que une México con Colombia a través de las naciones centroamericanas, con una extensión creciente de la violencia en Brasil.
\end{abstract}

Palabras clave: libertad de prensa / periodistas / violencia / homicidios / América Latina

\section{Half a Century Attacking Journalists. Murder and Disappearance Statistics in Latin America (1970-2015)}

Aвstract. In Latin America, since 1970, there has been more than one journalist killed or forcefully disappeared for reasons that have varied over time. From the very repressive measures of state terrorism in the years of military dictatorships, to the current combination of circumstances -corruption crime policy and organizers- that obstructs freedom of the press freedom through their own activities, sometimes of failed states. Impunity of attacks on the media and journalists are an incentive for those who use the silence of death as an authoritarian solution against civil liberties of democracy. At present, the geography of crime focuses on the area that connects Mexico to Colombia through Central American countries, with an increasing expansion of violence in Brazil.

Key words: freedom of the press / journalists / violence / murders / Latin America 
$\mathrm{P}$ ara las doctrinas que argumentan el Estado de derecho e integran las libertades públicas en el núcleo del modelo democrático, la libertad de prensa, como manifestación específica de la libertad de expresión, adquiere un valor determinante. Y lo es no solo porque forme parte del marco constitucional de un país, sino porque, en su actividad cotidiana, los medios y los periodistas operan con libertad. Más allá de la construcción retórica hecha a partir de los textos legales, los gobiernos están llamados a garantizar la libertad e impedir las obstrucciones al ejercicio profesional de los informadores, de modo que es la práctica, más que ningún otro aspecto, la que determina la naturaleza democrática de aquellos.

La cuestión que se analiza, relativa a las agresiones a periodistas con resultado de muerte o desaparición, encuentra en América Latina escenarios críticos donde los actos criminales se producen de forma reiterada, circunstancia que pone de manifiesto la existencia de sistemas incapaces, fallidos o colonizados por expresiones ilegítimas de poder. La opacidad, la injerencia sobre los medios y la creación de situaciones hostiles para el trabajo profesional se convierten en condiciones necesarias para la expansión del crimen organizado, la corrupción y la prevalencia de expresiones políticas ajenas a la cultura democrática.

En este artículo se analiza la evolución de un problema que, por su duración, puede calificarse de crónico, aunque no es uniforme en su geografía. Lo que hace cuatro décadas se circunscribió a una acción del terrorismo de Estado, básicamente focalizada en el hemisferio sur, en las tres últimas se ha ido desplazando, cada vez de forma más definida, al escenario de los narcopoderes, en las naciones latinoamericanas del hemisferio norte.

Aunque el problema tiene una importancia central, sorprende el relativamente escaso interés académico sobre una cuestión tan relevante en la configuración de los sistemas de medios en democracia, directamente relacionado con el estado de salud de la libertad de prensa. El enfoque queda relegado, con frecuencia, a una lectura gremial del problema o a la preocupación de iniciativas externas al ámbito académico, como si el abordaje sobre los medios pudiese eludir una amenaza que degrada y pervierte su papel en la construcción social y política.

\section{Libertad de prensa e imagen exterior}

Aun siendo América Latina un escenario muy diverso, con grandes diferencias en las culturas políticas y fuertes oscilaciones en los proyectos nacionales, hay una imagen dominante en materia de libertad de prensa, que describe una panorámica negativa sobre el conjunto de la región, sin distinción de matices. El asesinato de un periodista en Sinaloa, por ejemplo, alcanza al conjunto, percibido como una geografía escasamente evolucionada en materia de libertades públicas 
y desarrollo democrático. Las noticias de periodistas asesinados en América Latina, que durante la última década hacen referencia en gran medida a México, se han convertido en sucesos descontextualizados, que son recogidos por los grandes medios del mundo como una anomalía regional.

Esta impresión se corresponde también con las valoraciones de ciertos indicadores, de solo relativa fiabilidad, que relegan a la mayoría de las naciones latinoamericanas a posiciones que indican ausencia de libertad, más propias de los regímenes autoritarios. De acuerdo con la clasificación de Reporteros Sin Fronteras (RSF), con relación al año 2014, once naciones se encontrarían entre los países más alejados de los niveles de referencia en cuanto a la libertad de prensa. De 180 naciones evaluadas, además de Cuba, situada en el puesto 170, aparecen en la segunda mitad de la tabla Bolivia (94), Ecuador (95), Perú (104), Paraguay (105), Brasil (111), Venezuela (116), Guatemala (125), Colombia (126), Honduras (129) y México (152). Del resto de las naciones, solo Costa Rica (21), Uru- guay (26) y El Salvador (38) comparten posiciones con los países mejor valorados, mientras que, en una franja algo más rezagada, aparecen Argentina (55), Chile (58), República Dominicana (68), Nicaragua (71) y Panamá (87). En 2014, RSF introdujo la valoración desagregada de las agresiones a periodistas, con una relación encabezada por México (63,2 puntos), seguido de Venezuela $(60,8)$, Honduras $(60,6)$, Brasil $(56,7)$, Colombia $(55,5)$, Paraguay $(52,3)$, Cuba (52,3), Argentina (48,0), Ecuador $(39,5)$, Perú $(37,4)$, Bolivia $(35,6)$, Nicaragua $(28,9)$, República Dominicana $(28,3)$, Chile $(25,6)$ y El Salvador $(23,0)$. Solo Costa Rica, Uruguay y Panamá figuraban libres de agresiones.

Otro de los indicadores, el de la estadounidense Freedom House (FH), también clasifica a los países por su grado de libertad de prensa. En 2014, únicamente aparecían dos naciones latinoamericanas en un escenario de normalidad -Costa Rica y Uruguay-, otras cuatro eran calificadas de naciones no libres -Cuba, Venezuela, México y Ecuador-, y el resto figuraba con libertad restringida ${ }^{1}$.

1 No existe literatura crítica acerca de estos indicadores, los parámetros de medición que aplican y la misma naturaleza de las entidades que los abordan. En este sentido, cabe destacar la tesis de Ruth de Frutos, Indicadores mediáticos: Análisis crítico de los modelos de evaluación internacional (Universidad de Málaga, España, 2014), por cuanto plantea la necesidad de desarrollar mecanismos de medición no determinados necesariamente por una visión etnocéntrica anglosajona. Como acción complementaria del proyecto de investigación SEJ 2013-47933-c43p, del Plan Nacional de i+d del Ministerio de Economía y Competitividad de España, se está implementando un sistema de indicadores de libertad de prensa menos sujeto a los criterios hoy dominantes y a una visión que pudiese estar influenciada por valores mercantiles y de negocio, y no tanto por el anclaje de los medios en el sistema de libertades públicas. 
Tabla 1

Indicadores de RSF sobre libertad de prensa en América Latina (2002-2015)

\begin{tabular}{|c|c|c|c|c|c|c|c|c|c|c|c|c|c|}
\hline & 2002 & 2003 & 2004 & 2005 & 2006 & 2007 & 2008 & 2009 & 2010 & $2011-2$ & 2013 & 2014 & 2015 \\
\hline Argentina & 42 & 67 & 79 & 59 & 76 & 82 & 68 & 47 & 55 & 47 & 54 & 55 & 57 \\
\hline Bolivia & 48 & 51 & 76 & 45 & 16 & 68 & 115 & 95 & 103 & 108 & 109 & 94 & 94 \\
\hline Brasil & 54 & 71 & 66 & 63 & 75 & 84 & 82 & 71 & 58 & 99 & 108 & 111 & 99 \\
\hline Colombia & 114 & 147 & 134 & 128 & 131 & 126 & 127 & 126 & 145 & 143 & 129 & 126 & 128 \\
\hline Costa Rica & 15 & 24 & 35 & 41 & 29 & 21 & 22 & 30 & 29 & 19 & 18 & 21 & 13 \\
\hline Cuba & 134 & 165 & 166 & 161 & 165 & 165 & 169 & 170 & 167 & 167 & 171 & 170 & 169 \\
\hline Chile & 24 & 38 & 42 & 50 & 49 & 39 & 56 & 40 & 33 & 82 & 56 & 58 & 43 \\
\hline Ecuador & 20 & 42 & 67 & 87 & 68 & 56 & 75 & 84 & 102 & 104 & 119 & 95 & 108 \\
\hline El Salvador & 33 & 39 & 28 & 28 & 41 & 64 & 62 & 79 & 51 & 37 & 38 & 38 & 45 \\
\hline Guatemala & 83 & 99 & 68 & 86 & 90 & 104 & 101 & 106 & 77 & 98 & 95 & 125 & 124 \\
\hline Honduras & -- & 65 & 53 & 77 & 64 & 88 & 100 & 128 & 143 & 136 & 127 & 129 & 132 \\
\hline México & 75 & 74 & 96 & 135 & 132 & 136 & 140 & 138 & 136 & 149 & 153 & 152 & 148 \\
\hline Nicaragua & - & 36 & 52 & 68 & 69 & 47 & 60 & 76 & 83 & 72 & 78 & 71 & 74 \\
\hline Panamá & 49 & 54 & 61 & 67 & 39 & 54 & 57 & 55 & 81 & 113 & 111 & 87 & 83 \\
\hline Paraguay & 32 & 40 & 47 & 69 & 82 & 90 & 91 & 54 & 54 & 83 & 91 & 105 & 109 \\
\hline Perú & 36 & 55 & 124 & 116 & 113 & 117 & 108 & 85 & 109 & 115 & 105 & 104 & 92 \\
\hline R. Dominicana & - & 72 & 31 & 51 & 52 & 72 & 83 & 98 & 97 & 95 & 80 & 68 & 63 \\
\hline Uruguay & 21 & 25 & 45 & 46 & 57 & 38 & 43 & 29 & 37 & 32 & 27 & 26 & 23 \\
\hline Venezuela & 77 & 96 & 90 & 93 & 115 & 114 & 113 & 124 & 134 & 120 & 117 & 116 & 137 \\
\hline N. ${ }^{\circ}$ de países & 139 & 166 & 167 & 167 & 168 & 169 & 173 & 175 & 178 & 179 & 179 & 180 & 180 \\
\hline
\end{tabular}

Fuente: Reporteros Sin Fronteras (2002-2015)

Elaboración propia

\section{Aproximación estadística}

En 2005 se creó, en torno al proyecto Infoamérica (infoamerica.org), un observatorio de la libertad de prensa en América Latina, con alertas tomadas de diferentes asociaciones y organismos de control del libre ejercicio del periodismo, relativas a los atentados sufridos por los profesionales de la información desde 1970. Se ha hecho un repertorio histórico de más de mil periodistas muertos y desaparecidos de forma violenta, y se han identificado, con relativa precisión, las víctimas, los medios en los que trabajaban y las 
causas de las agresiones sufridas ${ }^{2}$. Con seguridad, una relación incompleta, tanto por aquellos casos que han podido pasar desapercibidos en los registros de víctimas o que, en su momento, al producirse en un contexto de opacidad y censura, fueron silenciados o no declarados, como por la inclusión de agresiones no siempre bien documentadas acerca de sus motivaciones o sobre la condición profesional de las víctimas.

Las organizaciones más conocidas en el registro de datos emplean distintos criterios, de forma que pueden dar la alerta de un periodista muerto y no recogerlo posteriormente en los repertorios estadísticos, al entender que no ha sido comprobada la naturaleza última del atentado y si este afectaba o no a la libertad de prensa, cuestiones no siempre sencillas de dirimir ${ }^{3}$.

De ese modo, las cifras dramáticas de muertos y desaparecidos quedan drásticamente reducidas, ya que la eficacia de la justicia no destaca en- tre las fortalezas de algunas naciones latinoamericanas, y son minoría los procesos que se resuelven, verifican la naturaleza del crimen e identifican a sus autores materiales e intelectuales.

En la tabla 2 se recogen cuatro fuentes estadísticas: Reporteros Sin Fronteras (RSF), Committee to Protect Journalists (CPJ), International Federation of Journalists (IFJ) e International Press Institute (IPI), que no son coincidentes en sus datos, pese a que los criterios generales de registro de casos son relativamente parecidos. La ausencia de verificaciones judiciales obliga a adoptar, en ocasiones, criterios de inclusión de víctimas que no se corresponden con la realidad más amplia del drama. Es cierto que el filtro depurador que discrimina los casos estrictamente relacionados con el ejercicio profesional es necesario, pero no siempre abordable $\mathrm{y}$, además, podría ensombrecer realidades ya enturbiadas por la opacidad de los sistemas.

2 El resultado de este trabajo se publicará en un libro promovido por la Cátedra Unesco de la Universidad de Málaga (España), bajo el título La violencia del silencio. Más libertad para matar que para informar.

3 Si se toma como referencia, por ejemplo, la apertura de un procedimiento judicial y la publicación de una sentencia, la mayoría de los casos pasaría a un gran limbo informativo. La falta de diligencia y eficacia institucional es notable en las naciones más afectadas por esta crisis, lo que relaciona violencia e impunidad con la inacción estructural del sistema. Recientemente, en México, uno de los casos emblemáticos y de mayor alarma social -el asesinato del periodista Gregorio Jiménez en Veracruz-, fue calificado por la Procuraduría General de Justicia como "conflicto personal entre vecinos", circunstancia calificada por la organización Article 19 como inaceptable y ofensiva. Con frecuencia, cuando la responsabilidad alcanza a los gobiernos, se trata de presentar el homicidio en otro contexto, incluso vinculado a la delincuencia común. 
Tabla 2

Muertes registradas por RSF, CPJ, FIJ e IPI (2002-2015)

\begin{tabular}{|c|c|c|c|c|c|c|c|c|c|c|c|c|c|c|c|c|}
\hline & & 2002 & 2003 & 2004 & 2005 & 2006 & 2007 & 2008 & 2009 & 2010 & 2011 & 2012 & 2013 & 2014 & $2015^{*}$ & Total \\
\hline \multirow{4}{*}{ Brasil } & RSF & 2 & 2 & 2 & 1 & 1 & 1 & & & 1 & 3 & 5 & 5 & 2 & 2 & 27 \\
\hline & CPJ & 2 & 2 & $2 / 1$ & & & 1 & & $0 / 1$ & 1 & $3 / 3$ & $4 / 1$ & $3 / 1$ & 3 & $3 / 1$ & 32 \\
\hline & FIJ & 2 & $3 / 1$ & 3 & 1 & 3 & 2 & 1 & 2 & 2 & 5 & 6 & 4 & 3 & 3 & 41 \\
\hline & IPI & 2 & 4 & 3 & 2 & 1 & 1 & 1 & 2 & 2 & 5 & 5 & 6 & 4 & 1 & 39 \\
\hline \multirow{4}{*}{ Colombia } & RSF & 3 & 4 & 1 & 1 & 3 & & & 1 & 2 & 1 & 1 & 1 & 2 & 1 & 21 \\
\hline & CPJ & $2 / 6$ & $5 / 1$ & 1 & 2 & $2 / 1$ & $0 / 1$ & & $1 / 2$ & $1 / 1$ & $0 / 1$ & $1 / 1$ & $1 / 0$ & $0 / 1$ & $0 / 2$ & 33 \\
\hline & FIJ & $3 / 5$ & $7 / 1$ & 3 & 3 & 5 & 1 & 1 & 4 & 3 & 1 & 3 & 3 & 3 & 3 & 49 \\
\hline & $\mid \mathrm{PI}$ & 15 & 9 & 1 & 2 & 3 & & & 6 & 3 & 1 & 3 & 2 & 2 & 1 & 48 \\
\hline \multirow{4}{*}{ Guatemala } & RSF & 1 & & & & 1 & & & & & & & & & 1 & 3 \\
\hline & CPJ & & 1 & & & $0 / 1$ & $0 / 1$ & & $0 / 2$ & & $0 / 1$ & & $0 / 2$ & & $1 / 1$ & 10 \\
\hline & FIJ & & $1 / 1$ & & & 2 & 2 & 1 & 3 & 2 & 1 & & 2 & & 2 & 17 \\
\hline & $|P|$ & & 2 & & & 1 & 1 & 1 & 1 & 2 & 1 & & 3 & & 1 & 13 \\
\hline \multirow{4}{*}{ Honduras } & RSF & & & & & & & 1 & & 3 & 3 & 2 & 3 & 1 & & 13 \\
\hline & CPJ & & $0 / 1$ & & & & 1 & & $0 / 2$ & $3 / 6$ & $0 / 4$ & $0 / 1$ & $0 / 2$ & $0 / 2$ & & 22 \\
\hline & FIJ & & 1 & & & & 1 & 1 & 3 & 10 & 7 & 2 & 3 & 6 & 3 & 36 \\
\hline & $|P|$ & & 1 & & & & 1 & 4 & 5 & 2 & 3 & 2 & 4 & & & 25 \\
\hline \multirow{4}{*}{ México } & RSF & & & 3 & 2 & 9 & 2 & 4 & 3 & 7 & 5 & 6 & 2 & 3 & 2 & 48 \\
\hline & CPJ & & & $3 / 1$ & $1 / 1$ & $2 / 5$ & $2 / 2$ & $2 / 4$ & $3 / 5$ & $3 / 7$ & $3 / 4$ & $2 / 4$ & $0 / 3$ & $2 / 1$ & $3 / 1$ & 64 \\
\hline & FIJ & $1 / 1$ & & 5 & $2 / 1$ & 10 & 6 & 10 & 13 & 10 & 11 & 10 & 4 & 5 & 7 & 94 \\
\hline & IPI & 3 & & 4 & 2 & 7 & 3 & 5 & 11 & 12 & 10 & 7 & 3 & 2 & 1 & 70 \\
\hline \multirow{4}{*}{ Paraguay } & RSF & & & & & & 1 & & & & 1 & & 1 & 2 & & 4 \\
\hline & CPJ & & & & & & 1 & & & & $0 / 1$ & & & 3 & & 4 \\
\hline & FIJ & & & & & & 1 & 1 & 1 & & & & 2 & 4 & & 9 \\
\hline & IPI & & & & & & 1 & & 1 & & 1 & & 2 & 2 & & 7 \\
\hline \multirow{4}{*}{ Perú } & RSF & & & 2 & & & 1 & & & & 3 & & & & & 6 \\
\hline & CPJ & & & 2 & & & 1 & & & & $1 / 2$ & & $0 / 1$ & $0 / 1$ & & 8 \\
\hline & FIJ & 3 & & 2 & & & 1 & & & & 1 & & & 2 & & 6 \\
\hline & IPI & & & 2 & & & 1 & & & & 3 & 4 & 1 & 1 & & 12 \\
\hline \multirow{4}{*}{$\begin{array}{l}\text { Resto de } \\
\text { países }\end{array}$} & RSF & 1 & & 3 & 1 & 2 & & 2 & 2 & & 2 & 1 & & & & 14 \\
\hline & CPJ & 1 & & $3 / 1$ & 1 & $6 / 2$ & $-/ 1$ & $1 / 2$ & 2 & & $3 / 2$ & 1 & & & & 26 \\
\hline & FIJ & 2 & & 7 & $1 / 1$ & 6 & 1 & 4 & 3 & 2 & 5 & 1 & 1 & 2 & 1 & 37 \\
\hline & IPI & 1 & 1 & 4 & 1 & 2 & 1 & 2 & 2 & 2 & 3 & 1 & 1 & 1 & & 20 \\
\hline \multirow{4}{*}{ Totales } & RSF & 7 & 6 & 11 & 5 & 16 & 5 & 7 & 6 & 13 & 18 & 15 & 12 & 10 & 6 & 137 \\
\hline & CPJ & 10 & 10 & 14 & 5 & 14 & 11 & 9 & 18 & 22 & 28 & 15 & 13 & 13 & 12 & 194 \\
\hline & FIJ & 17 & 16 & 19 & 9 & 29 & 15 & 19 & 30 & 29 & 31 & 22 & 19 & 25 & 19 & 299 \\
\hline & IPI & 21 & 17 & 14 & 7 & 16 & 10 & 13 & 28 & 24 & 27 & 23 & 23 & 12 & 4 & 239 \\
\hline
\end{tabular}

* Hasta el 15 de agosto de 2015. En los datos de CPJ y FIJ se contabilizan dos opciones, muertes por motivos confirmados y bajo investigación (p. ej.: 1/1), si bien ambas cifras aparecen en los totales. Fuente: RSF, CPJ, FIJ e IPI (2002-2015)

Elaboración propia 
En cualquier caso, el número de agresiones a periodistas claramente identificadas como actos de violencia común es tan elevado en México, Guatemala, Honduras y Colombia, que refleja, asimismo, aspectos fallidos de la seguridad pública, que suelen participar del mismo clima de impunidad y crisis institucional en el que se producen las muertes objeto de este análisis.

En el caso de México, los registros no son siempre los más precisos. Las informaciones gremiales suelen incluir todas las muertes violentas, sin una depuración clara de las circunstancias, de modo que pueden atribuir una muerte en un accidente fortuito a una agresión contra el libre ejercicio profesional, sin distinguir, en otras ocasiones, las intersecciones y la contaminación entre política, justicia, periodismo y crimen organizado. La lógica analítica se rompe con frecuen- cia cuando se ausculta un sistema fallido, trazado por estructuras cómplices en un escenario donde la impunidad resulta ser el factor determinante de la violencia. Son frecuentes, pero no siempre evidentes, los casos de 'narcoperiodistas ${ }^{4}$, así como la existencia de medios penetrados por los intereses de los poderosos cárteles de la droga. Un problema que igualmente se vivió en Colombia. En 1999, Javier Darío Restrepo escribía que cuando un periodista era asesinado en su país se buscaba al asesino en dos direcciones.

Una, como un hecho relacionado con su trabajo periodístico, y la segunda que no descarta "que su muerte pueda explicarse por su vinculación con el narcotráfico". Y añadía: "Esa sola sospecha es una muerte moral que se agrega a su muerte física. Son personas que el mismo día mueren dos veces" ${ }^{\prime \prime}$.

4 El término se emplea en México, Colombia y Paraguay, entre otros países, y se hizo muy presente a raíz de la detención de periodistas mexicanos de Televisa en Nicaragua, sobre los que se había divulgado un video en el que aparecían junto al jefe del cártel de Los Caballeros Templarios. El corresponsal de Excélsior en Culiacán, Martínez Montenegro, es considerado el primer periodista del que se tiene constancia de presuntos vínculos con el crimen organizado (Raymundo Riva Palacio, "Narcoperiodistas", en El Financiero, México, D. F., 25-9-2014). La muerte, en 1978, de Montenegro, que provocó una huelga de periodistas, es un caso claro de la ambigüedad con la que operan ciertos profesionales vinculados al crimen organizado, ya que aparentemente su trabajo consistía en la denuncia de la corrupción política y sus vínculos con el narcotráfico. En agosto de 2015 fue asesinado Juan Heriberto Santos Cabrera, en Orizaba, Veracruz, en el que podría ser, según la versión de las autoridades gubernativas, el caso más reciente de 'narcoperiodista'. Profesional, durante años, de Televisa, fue muerto junto al jefe del cártel de Los Zetas en la zona.

5 "Noticias de alto riesgo" (1999), recogido en Sala de Prensa, año 2, vol. 2, en http://www. saladeprensa.org/art31.htm [Consultado: 29-6-2015]. 
En las páginas que siguen, se recogen los datos referidos a los atentados contra periodistas durante los últimos 45 años. Como criterio para la inclusión en las estadísticas se ha tomado el de trabajadores de medios de comunicación de todo tipo, privados, públicos y comunitarios, adscritos a los núcleos de redacción y dirección, con exclusión de aquellos que, aun al servicio de los medios, lo hacen en talleres de impresión, procesos de producción y distribución, y venta pública de ejemplares. Se han excluido en torno a un centenar de casos ajenos al perfil descrito en aquellas fuentes en las que aparecían referidos, tanto en las etapas de las dictaduras militares como en los casos más recientes. Se mantienen, no obstante, periodistas cuyo ejercicio profesional pudiera estar sujeto a intereses espurios o directamente relacionados con el crimen organizado. La ausencia de datos fiables en situaciones de quiebra ética e institucional, donde representantes públicos pueden aparecer implicados en los actos criminales, dificulta el discernimiento sobre el perfil estrictamente profesional de la víctima y la naturaleza del asesinato. En algunos casos, la muerte se produce cuando el periodista relacionado con el crimen organizado decide abandonar la posición, precisamente para evitar que divulgue lo que conoce.

Debe advertirse, no obstante, que la proyección exterior de los crímenes a periodistas en América Latina se basa en la publicidad mediática de los mismos, no en la verificación de las causas de la agresión y en la acción de la justicia.

\section{La anomalía latinoamericana}

Por razones diversas y en escenarios distintos, la presión y el hostigamiento sobre los periodistas en el ejercicio profesional ha sido una constante en América Latina. Una práctica que, en muchos casos, ha supuesto el secuestro, la desaparición y la muerte violenta, y ha dado argumento a la que podría definirse como la 'anomalía latinoamericana'. Una anomalía relacionada con el desarrollo democrático, al tiempo que una manifestación de la resistencia de instancias de poder fáctico a la transparencia, la crítica, el debate $y$, en definitiva, a la democracia. $\mathrm{El}$ asesinato de 1027 periodistas desde 1970, fecha que se toma como punto de partida estadístico, superan una media de 22,5 casos al año. Lo que podría parecer una resultante nutrida fuertemente por los años de las dictaduras militares y de las luchas armadas, lejos de los escenarios de estabilidad democrática, queda desmentida por los datos de los últimos años, que acentúan el dramatismo de la crisis.

La corrupción política y el narcopoder han ido tomando el relevo al terrorismo de Estado de los años setenta, y a las luchas armadas de las décadas siguientes. En 2014, se registraron 31 homicidios de periodistas en ocho naciones, con fuerte peso estadístico de México y Honduras. En los diez prime- 
ros meses de 2015 se contabilizaban 29 casos en seis naciones, con mayor protagonismo de México, Honduras y Brasil. Por ello, aunque el fenómeno se ha visto drásticamente reducido en algunos países, especialmente en los del hemisferio sur, hay razones para seguir hablando de la 'anomalía latinoamericana'.

El asesinato de periodistas constituye "la forma de censura más extrema" (OEA, 2008, p. 11)6. Es "la censura del fuego" (Lozano y Gutiérrez, 2004). Las muertes y las desapariciones de periodistas no agotan la gama de las amenazas, ni hacen visibles aquellas situaciones que no son denunciadas por el ambiente de desconfianza, temor, desprotección e impunidad. Antes de llegar al asesinato de un periodista, suele suceder el acoso sobre él y sus familiares, las agresiones físicas, la difamación, las extorsio- nes. Todo ello, con independencia de la fuente agresora, conduce a la quiebra de la independencia profesional, a la renuncia de la actividad periodística, al exilio, cuando no a la claudicación y a la entrega a las condiciones que establece el enemigo. De este modo, se configuran sistemas de medios intervenidos, carentes de libertad y regidos por los mecanismos del miedo que conducen a la autocensura?

La estrategia de la agresión, que en los últimos años, se centra en el hemisferio norte, con fuerte peso de México en las estadísticas, revela que las víctimas suelen ser modestos trabajadores, en condiciones laborales precarias, que viven en zonas alejadas de los grandes medios centrales, y que, en la mayoría de las ocasiones, tienen un carácter local y comunitario.

6 El informe de la Relatoría Especial para la Libertad de Expresión (2008) añade: “El asesinato de un periodista no solo vulnera en forma grave su derecho a la vida, sino que suprime en forma radical su derecho a expresarse libremente y vulnera el derecho de las sociedades y de sus ciudadanos y ciudadanas a buscar y recibir informaciones e ideas de toda índole. La vulneración de la dimensión social y colectiva del derecho a la libertad de expresión se hace aún más grave por el efecto de autocensura que tiene, sobre los demás trabajadores de la comunicación social, el asesinato de un periodista cometido en razón de su labor. La impunidad de estos crímenes acentúa la autocensura y constituye, también, una seria vulneración del derecho a la libertad de expresión en su dimensión individual y en su dimensión colectiva".

7 Una de las consecuencias del acoso psicológico sobre las redacciones es el exilio o el abandono de la actividad profesional, aspectos no siempre bien recogidos por los indicadores, ya que muchas de estas decisiones personales se amparan en el sigilo para evitar la persecución. Ya en el período de las dictaduras militares fueron muy numerosos los exilios de periodistas brasileños, uruguayos, chilenos y argentinos. Este mecanismo de supervivencia se repitió en Colombia (Robinson et al., 2009, p. 7 y ss.) y se conoce actualmente en Centroamérica y México. En este último país, entre 2010 y 2015 se han contabilizado 34 desplazados, aunque esta es una cifra poco real, ya que muchos no comunican la situación para evitar problemas. Según Article 19, tras el asesinato de Regina Martínez, huyeron de Veracruz 23 profesionales. 
En la actualidad, en el caso de Méxi$\mathrm{co}$, resultan infrecuentes las agresiones más violentas a trabajadores de los medios en las grandes ciudades o sobre los periodistas relevantes y de mayor influencia social. Aquí, las injerencias son más sutiles. No ocurrió así durante las dictaduras militares, con una represión netamente urbana, ni en algunas de las agresiones en Colombia, especialmente en las acciones de los cárteles de la droga sobre los grandes medios de Bogotá y Cali.

Aunque las muertes y desapariciones, por su naturaleza de violencia extrema, causen mayor alarma social, estas solo representan una parte, la más dramática, de todo un repertorio de coacciones y obstrucciones sobre los medios y los periodistas. Si es posible identificar el número aproximado de asesinatos y desapariciones, es más difícil cuantificar otro tipo de agresiones e injerencias que llevan a doblegar la voluntad de quien informa, a excluirlo de la actividad profesional, o a obligarle a escribir al dictado de otros y emplear, de forma habitual, mecanismos de control y autocensura. Respuestas propias de la naturaleza humana bajo la presión y el miedo, lejos del mito romántico que atribuye heroicidad al periodista, sin desmerecer por ello a quienes, en su riesgo diario, terminan por mostrar rasgos heroicos.

En general, los sistemas de medios de las naciones castigadas por la violencia aparecen muy debilitados y, en su memoria profesional, pesan las ex- periencias contrarias al libre ejercicio del periodismo. El efecto de los atentados sobre los periodistas es la esterilización de la libertad profesional. En diciembre de 2012, el portal de noticias de Veracruz Plumas Libres lanzó una alerta por la que renunciaba a publicar determinadas informaciones "por falta de garantías para el ejercicio del periodismo" y respeto a la integridad de sus redactores, y añadía: "Esperamos la comprensión de la sociedad ante un escenario de descomposición creciente para el periodismo en Veracruz" (Nuestra Aparente Rendición, 2013).

La Red de Periodistas de a Pie recopiló testimonios de profesionales afectados, entre los que se podía leer:

La psicosis se ha apoderado del periodismo en Veracruz (...) Ante el éxodo masivo de reporteros policiacos, las mesas de redacción se quedaron con el problema de cómo llenar esa sección (...) Nadie sale a informar desde aquel 26 de julio, día en que se encontró el cuerpo decapitado de Yolanda Ordaz (...) La investigación y el quehacer periodístico han quedado en segundo plano. (Nuestra Aparente Rendición, 2013)

La periodista mexicana Lydia Cacho, premio mundial Libertad de Prensa de Unesco 2008, ha reflejado las sensaciones que tuvo tras una de las amenazas que recibió: "El miedo se coló entre mis sueños (...) Vuelven a mi mente las palabras de la penúltima amenaza de muerte que recibí por correo electrónico. Primero, entregarían 
mis manos a mi pareja; luego, darían la cabeza a mi padre"

Las amenazas están implícitas en la ejemplaridad de las imágenes que, en sí, son un acto más de violencia, y constituyen una advertencia que, en ocasiones, narran las notas que acompañan a los cadáveres torturados, decapitados, descuartizados. La imagen viva del miedo y la lógica del terrorismo provocan un efecto directo sobre redacciones desprotegidas, mal pagadas, desasistidas por el abandono, cuando no por la hostilidad añadida de las instituciones llamadas a protegerlas y a garantizar la libertad de prensa como requerimiento del Estado de derecho.

Las modalidades de acoso sobre los periodistas son muy variadas $y$, en ocasiones, nacen de las prácticas restrictivas establecidas desde la propiedad y la dirección de los mismos medios. Es decir, muchas de las presiones externas no llegan directamente al periodista, sino que aparecen integradas en la línea editorial y en la agenda del medio. No obstante, se han tipi- ficado numerosas modalidades que, en muchos casos, pueden catalogarse como amenazas, y suelen producirse, por regla general, en las fases previas al asesinato de los profesionales.

Sobre la importancia de estas manifestaciones basta referir los datos que, en un período de relativa normalización en Colombia, ofrece la Fundación para la Libertad de Prensa (FLIP). En la tabla 3 se resumen las irregularidades registradas durante cinco años (2010-2014), tiempo en el que se produjeron seis homicidios de periodistas.

Por cada muerte se denunciaron otras 147 violaciones de la actividad profesional, dominadas por las amenazas, con 417 víctimas (69 por cada asesinato) y la obstrucción al trabajo periodístico. Formas de hostigamiento habitual que, sin alcanzar el dramatismo de los atentados mortales, minan la moral de los informadores y pueden conducir sus prácticas constructivas a soluciones reguladas por el miedo, la autocensura y el dictado de intereses ajenos a los de sus audiencias (Cardona, 2009) ${ }^{9}$.

8 “No quiero perder la cabeza", en Pen International, 2013 (http://www.pen-international. org/no-quiero-perder-al-cabeza/) [Consultado: 2-08-2015].

9 La presión sobre los periodistas colombianos durante más de medio siglo de guerra civil está descrita por hechos dramáticos en los que se ha entrecruzado el fuego de las autoridades del Estado, las guerrillas, los paramilitares y los cárteles de la droga. El suceso que alcanzó mayor eco mundial, en un escenario con más de 170 muertos, fue el asesinato de Guillermo Cano Isaza, director de El Espectador, el 17 de diciembre de 1986, tres años antes del atentado del cártel de Medellín que destruyó la redacción del diario. La Unesco instituyó, en 1997, el Premio Mundial de la Libertad de Prensa Guillermo Cano, en honor del periodista que hizo frente a la barbarie del narcoterrorismo con la palabra. 
Tabla 3

Indicadores FLIP sobre agresiones a periodistas en Colombia (2010-2015)

\begin{tabular}{|c|c|c|c|c|c|c|c|c|c|c|c|c|}
\hline & & 2006 & 2007 & 2008 & 2009 & 2010 & 2011 & 2012 & 2013 & 2014 & 2015 & Total \\
\hline \multirow{2}{*}{ Agresión } & Violaciones & & & & & & & 31 & 10 & 22 & 11 & 74 \\
\hline & Víctimas & & & & & & & 38 & 30 & 32 & 13 & 113 \\
\hline \multirow{2}{*}{ Amenaza } & Violaciones & 77 & 85 & 71 & 65 & 47 & 93 & 78 & 52 & 61 & 40 & 669 \\
\hline & Víctimas & 88 & 95 & 93 & 93 & 60 & 119 & 91 & 75 & 72 & 51 & 835 \\
\hline \multirow{2}{*}{ Asesinato } & Violaciones & 3 & 2 & & 1 & 2 & 1 & 1 & 2 & & 2 & 14 \\
\hline & Víctimas & 3 & 2 & & 1 & 2 & 1 & 1 & 2 & & 2 & 14 \\
\hline Atentado contra & Violaciones & 1 & 2 & 2 & & 3 & 2 & 3 & 1 & 1 & 4 & 19 \\
\hline infraestructura & Víctimas & 1 & 2 & 2 & & 2 & 2 & 3 & 0 & 1 & 8 & 21 \\
\hline \multirow{2}{*}{ Desplazamiento } & Violaciones & & & & 1 & 1 & & 5 & 1 & 1 & 1 & 10 \\
\hline & Víctimas & & & & 1 & 1 & & 6 & 1 & 1 & 1 & 11 \\
\hline \multirow{2}{*}{ Detención ilegal } & Violaciones & 5 & 2 & & 2 & & 2 & 8 & 4 & 6 & 1 & 30 \\
\hline & Víctimas & 8 & 2 & & 3 & & 2 & 9 & 10 & 6 & 1 & 41 \\
\hline \multirow{2}{*}{ Estigmatización } & Violaciones & & & & 1 & & 1 & 1 & 7 & 3 & 14 & 27 \\
\hline & Víctimas & & & & 1 & & 1 & 1 & 7 & 3 & 17 & 30 \\
\hline \multirow{2}{*}{ Exilio } & Violaciones & 10 & 7 & 2 & 3 & 2 & 2 & 1 & 3 & 1 & & 31 \\
\hline & Víctimas & 10 & 7 & 2 & 3 & 1 & 2 & 1 & 3 & 1 & & 30 \\
\hline \multirow{2}{*}{ Herido en cobertura } & Violaciones & & 1 & 1 & 1 & & 1 & 2 & 2 & & & 8 \\
\hline & Víctimas & & 1 & 1 & 2 & & 1 & 2 & 2 & & & 9 \\
\hline \multirow{2}{*}{$\begin{array}{l}\text { Obstrucción al trabajo } \\
\text { periodístico }\end{array}$} & Violaciones & 17 & 25 & 21 & 39 & 30 & 9 & 23 & 29 & 34 & 25 & 342 \\
\hline & Víctimas & 20 & 70 & 25 & 91 & 50 & 10 & 15 & 55 & 46 & 56 & 438 \\
\hline \multirow{2}{*}{ Secuestro } & Violaciones & 3 & 1 & 1 & 3 & 2 & & 2 & 1 & & 1 & 14 \\
\hline & Víctimas & 4 & 2 & 1 & 6 & 7 & & 2 & 1 & & 1 & 24 \\
\hline \multirow{2}{*}{$\begin{array}{l}\text { Tentativa de } \\
\text { homicidio }\end{array}$} & Violaciones & & & & & 1 & & 2 & 1 & 1 & & 5 \\
\hline & Víctimas & & & & & 1 & & 3 & 1 & 1 & & 6 \\
\hline \multirow{2}{*}{$\begin{array}{l}\text { Trato inhumano o } \\
\text { degradante }\end{array}$} & Violaciones & 24 & 37 & 31 & 27 & 29 & 21 & & & & 2 & 171 \\
\hline & Víctimas & 32 & 80 & 56 & 38 & 45 & 23 & & & & 2 & 276 \\
\hline \multirow{2}{*}{ Otras } & Violaciones & & & & & & & 1 & 2 & 2 & 1 & 6 \\
\hline & Víctimas & & & & & & & 1 & 1 & 2 & 1 & 5 \\
\hline \multirow{2}{*}{ Total } & Violaciones & 140 & 162 & 129 & 143 & 117 & 132 & 159 & 123 & 132 & 102 & 1339 \\
\hline & Víctimas & 166 & 261 & 180 & 239 & 169 & 161 & 193 & 194 & 165 & 153 & 1881 \\
\hline
\end{tabular}

Nota. Ha sido eliminado el campo "violencia sexual" por no registrar ninguna incidencia.

Fuente: FLIP

Elaboración propia 
Cabe suponer que el número de denuncias solo abarca una parte de los hechos irregulares y que el silencio que buscan quienes hostigan a los periodistas se extiende también ante muchos casos de agresiones físicas o psicológicas sin que se produzcan denuncias. La desconfianza suele basarse en la experiencia percibida de la impunidad crónica.

Un informe de la organización Article 19 -Estado de silencio- sobre las agresiones a periodistas en México, refiere 330 episodios documentados en 2013 y 326 en 2014, lo que supone una agresión constatada cada 27 horas. En 2014, las agresiones físicas y los daños materiales fueron las de mayor registro, con el $43 \%$ de los casos, seguidas de las intimidaciones (16 $\%)$, las detenciones arbitrarias (14\%) y las amenazas (13\%). Del total de los registros, el $48 \%$ fue atribuido a funcionarios públicos, responsables del mayor número de ataques a la prensa durante 2014. Al tiempo, el estudio (Article 19, 2015, p. 20) revela que, más allá de los escenarios habituales de la violencia extrema (muertes y desapariciones), en el Distrito Federal se produjo el mayor número de agresiones (26\%), por delante de Quintana Roo (12,9), Veracruz $(12,6)$, Guerrero $(8,6)$ y Oaxaca $(6,7)$.

En Guatemala, el Observatorio de los Periodistas de Cerigua recoge con detalle las denuncias registradas, entre las que sobresalen, de forma destacada, las amenazas y las agresiones físicas ${ }^{10}$.

\section{Ámbito geográfico y evolución de las agresiones}

En el último medio siglo se pueden distinguir distintos períodos en cuanto a la violencia sobre los trabajadores de los medios. En la década de 1970, signada por los regímenes militares que, bajo la estrategia estadounidense, desplegaron el Plan Cóndor, se asistió a una esterilización ideológica de amplio espectro, que no solo afectó a los periodistas, y que puso especial énfasis en todos aquellos que eran asociados a posiciones calificadas de revolucionarias y terroristas (Schindel, 2012; Elías, 2005; Salomone, 1999; Oesterheld, Sajón y Suárez, 1999; Blaustein y Zubieta, 1998).

Como ya se ha anticipado, la violencia contra los periodistas en América Latina ha estado sujeta a distintos vectores de hostilidad, determinados por razones que van desde la acción represiva de las dictaduras militares a la estrategia del crimen organizado, si bien en este último caso, y en ello es muy ilustrativa la realidad mexicana y de algunas naciones centroamericanas, a la ineficacia de las instituciones se une la acción directa de las estructuras fallidas del Estado (Article 19, 2015, 2008;

10 Véase $<\mathrm{http}: / /$ cerigua.org/article/mapa-de-las-agresiones-a-la-libertad-de-expresion/>. 
Cencos, 2012; Moncada, 2012; Acosta, 2012; Gibons y Spratt, 2011).

Lo que empezó siendo, en términos de alarma internacional, la obra de regímenes militares, fenómeno muy focalizado en el hemisferio sur, donde se produjeron más del $82 \%$ de las muertes y desapariciones, cambió de orientación geográfica en las décadas siguientes. Fue entonces cuando las naciones del hemisferio norte polarizaron, en valores siempre superiores al $70 \%$, la estadística de la violencia (véase la tabla 4). No obstante, a pesar de una cier- ta constante en los registros de muertes y desapariciones, en términos relativos, como consecuencia del incremento de población, el número de casos por millón de habitantes ha descendido de 0,82 , en la década de los setenta, a 0,43 en la primera década del siglo XxI. Asimismo, se observa un claro contraste hemisférico, con predominio del norte en los valores críticos, donde el índice relativo alcanzó 1,29 en los años ochenta $y$, ya en la primera década del siglo xxI, descendió 0,80 , pero casi seis veces superior al 0,14 del sur.

Tabla 4

Muertes violentas según hemisferio y valor demográfico relativo (1970-2015)

\begin{tabular}{|c|c|c|c|c|c|c|c|}
\hline & & $1970-79$ & $1980-89$ & $1990-99$ & $2000-09$ & $2010-15^{*}$ & $1970-2015^{*}$ \\
\hline \multirow{5}{*}{ Hemisferio norte } & Habitantes (en millones) & 112,1 & 141,4 & 172,0 & 203,9 & 236,3 & \multirow{5}{*}{$\begin{array}{l}669 \\
65,1\end{array}$} \\
\hline & \% sobre total región & 41,8 & 42,0 & 41,9 & 42,6 & 43,1 & \\
\hline & Periodistas $\mathrm{m} / \mathrm{d}$ & 41 & 183 & 130 & 164 & 151 & \\
\hline & $\%$ sobre total & 18,6 & 80,6 & 72,2 & 80,4 & 77,0 & \\
\hline & M/D por millón habitantes & 0,36 & 1,29 & 0,76 & 0,80 & 0,64 & \\
\hline \multirow{5}{*}{ Hemisferio sur } & Habitantes (en millones) & 156,1 & 195,3 & 238,6 & 275,2 & 311,7 & \multirow{5}{*}{$\begin{array}{l}358 \\
34,9\end{array}$} \\
\hline & \% sobre total región & 58,2 & 58,0 & 58,1 & 57,4 & 56,9 & \\
\hline & Periodistas $\mathrm{m} / \mathrm{d}$ & 179 & 44 & 50 & 40 & 45 & \\
\hline & $\%$ sobre total & 81,4 & 19,4 & 27,8 & 19,6 & 23,0 & \\
\hline & M/D por millón habitantes & 1,15 & 0,22 & 0,21 & 0,14 & 0,14 & \\
\hline \multirow{3}{*}{$\begin{array}{l}\text { Total } \\
\text { Latina }\end{array}$} & Habitantes (en millones) & 268,2 & 336,7 & 410,6 & 479,1 & 548,0 & \multirow{3}{*}{1027} \\
\hline & Periodistas M/D & 220 & 227 & 180 & 204 & 196 & \\
\hline & M/D por millón habitantes & 0,82 & 0,67 & 0,44 & 0,43 & 0,36 & \\
\hline
\end{tabular}

\section{* Hasta 15-10-2015}

Datos de población, Indicadores Mundiales para el Desarrollo del Banco Mundial

Fuente: Observatorio Latinoamericano de la Libertad de Prensa (BDN/Infoamérica 2005-2015) 
Las cifras que aparecen en las tablas 4 a 10, relativas al período 1970-2015, con un registro total de 1027 casos de periodistas muertos y desaparecidos, se corresponden con los que están personalizados documentalmente en la base de datos de Infoamérica, de acceso libre a través de Internet ${ }^{11}$.
La primera década analizada (tabla 5) está descrita por el terrorismo de Estado. Los datos estadísticos reflejan las ejecuciones sin juicio previo, asesinatos, torturas y secuestros basados en criterios de limpieza ideológica. Sobresale Argentina, con 115 casos, 85 de ellos en solo dos años (1976 y 1977),

Tabla 5

Periodistas muertos y desaparecidos en América Latina (1970-1979)

\begin{tabular}{|c|c|c|c|c|c|c|c|c|c|c|c|}
\hline & 1970 & 1971 & 1972 & 1973 & 1974 & 1975 & 1976 & 1977 & 1978 & 1979 & Total \\
\hline Argentina & & & & 1 & 6 & 6 & 50 & 35 & 13 & 4 & 115 \\
\hline Bolivia & & 2 & & & & & & & & & 2 \\
\hline Brasil & 2 & 1 & 3 & 4 & 5 & 5 & 3 & & & & 23 \\
\hline Chile & & & & 14 & 9 & 1 & 1 & 1 & & & 26 \\
\hline Colombia & & & & & & & & 1 & & 5 & 6 \\
\hline \multicolumn{12}{|l|}{ Costa Rica } \\
\hline \multicolumn{12}{|l|}{ Cuba } \\
\hline \multicolumn{12}{|l|}{ Ecuador } \\
\hline \multicolumn{12}{|l|}{ El Salvador } \\
\hline Guatemala & 5 & 1 & & & 2 & 3 & 1 & & 5 & 2 & 19 \\
\hline \multicolumn{12}{|l|}{ Honduras } \\
\hline México & 1 & 1 & & 1 & & 1 & 1 & 1 & 2 & 4 & 12 \\
\hline Nicaragua & & & & & & & & & 1 & 1 & 2 \\
\hline \multicolumn{12}{|l|}{ Panamá } \\
\hline \multicolumn{12}{|l|}{ Paraguay } \\
\hline \multicolumn{12}{|l|}{ Perú } \\
\hline R. Dominicana & & & & 1 & & 1 & & & & & 2 \\
\hline Uruguay & & & & & & & 8 & 4 & & 1 & 13 \\
\hline \multicolumn{12}{|l|}{ Venezuela } \\
\hline Total & 8 & 5 & 3 & 21 & 22 & 17 & 64 & 42 & 21 & 17 & 220 \\
\hline
\end{tabular}

En Chile y Argentina no se incluyen los numerosos estudiantes de periodismo muertos y desaparecido Fuente: Observatorio Latinoamericano de la Libertad de Prensa (BDN/Infoamérica 2005-2015)

11 El Observatorio Latinoamericano de la Libertad de Prensa recoge, en forma personalizada, la información de los 1027 casos, al 15 de octubre de 2015, referidos en las estadísticas con identificación de las víctimas de muertes y desapariciones, medio en el que trabajaba el periodista, fecha del suceso y otras circunstancias (http://www.infoamerica.org/libex/libex_portada.htm). 
por delante de Chile (26), Brasil (23) y, en menor medida Uruguay (13), cuyos periodistas, exiliados en Argentina a raíz de la dictadura cívico-militar de su país (1973), fueron asesinados, la mayoría de ellos en Buenos Aires, en operaciones coordinadas al iniciarse el régimen militar argentino. En este período murieron prestigiosos profesionales, de un perfil ideológico marcado y en el ámbito urbano de los medios. En 1976, América Latina alcanzó la cifra récord de 64 periodistas muertos o desaparecidos, 62 de ellos en las dicta- duras militares del Sur, con un fuerte protagonismo argentino (50).

Pasado el período central de las dictaduras militares, el valor estadístico de la violencia contra los periodistas se desplazó hacia el hemisferio norte. En la década de los ochenta (tabla 6), las naciones del hemisferio sur redujeron su peso, ya que solo registraron 44 de los 227 casos de América Latina, es decir, el 19,4\%. Se inició el protagonismo de Colombia (41 muertos), como consecuencia del recrudecimiento armado de la lucha civil y

Tabla 6

Periodistas muertos y desaparecidos en América Latina (1980-1989)

\begin{tabular}{|c|c|c|c|c|c|c|c|c|c|c|c|}
\hline & 1980 & 1981 & 1982 & 1983 & 1984 & 1985 & 1986 & 1987 & 1988 & 1989 & Total \\
\hline Argentina & 1 & & 1 & & & & & & & & 2 \\
\hline Bolivia & 1 & & & & & & & & & & 1 \\
\hline Brasil & & & 3 & & 2 & & 1 & & 2 & 4 & 12 \\
\hline Chile & & & & 1 & 2 & & 1 & & & & 4 \\
\hline Colombia & 3 & & 1 & 4 & 4 & & 7 & 4 & 5 & 13 & 41 \\
\hline Costa Rica & & & & & 1 & & & & & & 1 \\
\hline \multicolumn{12}{|l|}{ Cuba } \\
\hline Ecuador & & & & & & & & & & 1 & 1 \\
\hline El Salvador & 10 & 11 & 5 & 1 & 2 & & & & & 8 & 37 \\
\hline Guatemala & 30 & 19 & 9 & & & 3 & & & 1 & 1 & 63 \\
\hline Honduras & & 1 & & 2 & & & & & 1 & & 4 \\
\hline México & 2 & & & 2 & 2 & 2 & 6 & 4 & 5 & 9 & 32 \\
\hline Nicaragua & & & & & 2 & & & 1 & & & 3 \\
\hline Panamá & & & & & & & & & & 1 & 1 \\
\hline \multicolumn{12}{|l|}{ Paraguay } \\
\hline Perú & & & 1 & 8 & 3 & 2 & & 1 & 3 & 6 & 24 \\
\hline R. Dominicana & & 1 & & & & & & & & & 1 \\
\hline \multicolumn{12}{|l|}{ Uruguay } \\
\hline \multicolumn{12}{|l|}{ Venezuela } \\
\hline Total & 47 & 32 & 20 & 18 & 18 & 7 & 15 & 10 & 17 & 43 & 227 \\
\hline
\end{tabular}

Fuente: Observatorio Latinoamericano de la Libertad de Prensa (BDN/Infoamérica 2005-2015) 
las tensiones derivadas del narcotráfico. En México, se acentuaron las prácticas endémicas en el hostigamiento de periodistas (32), un fenómeno que no era nuevo en la historia del país, y en menor medida aparece Perú (24). Sin embargo, en esta década sobresale la violencia desatada en Centroamérica, con 100 periodistas muertos y desaparecidos, de ellos 37 en la guerra civil de El Salvador y en el conflicto armado interno de Guatemala (63). Las tensiones se trasladan al hemisferio norte, pero aún predominan la confrontación política y las luchas armadas como factores determinantes de las muertes de periodistas.

Durante la década de los noventa (tabla 7), con menos víctimas (180) que las dos anteriores, se mantuvieron las tensiones armadas como origen de las muertes, pero el crimen organizado comenzó a adquirir un protagonismo mucho mayor, especialmente en Colombia, donde se contabilizaron un total de 62 muertes y desapariciones, la cifra más elevada de su secuencia estadística, muy por delante de lo re-

Tabla 7

Periodistas muertos y desaparecidos en América Latina (1990-1999)

\begin{tabular}{|c|c|c|c|c|c|c|c|c|c|c|c|}
\hline & 1990 & 1991 & 1992 & 1993 & 1994 & 1995 & 1996 & 1997 & 1998 & 1999 & Total \\
\hline Argentina & & & & 1 & & & & 1 & & 1 & 3 \\
\hline \multicolumn{12}{|l|}{ Bolivia } \\
\hline Brasil & & 2 & 1 & & 2 & 7 & 3 & 3 & 2 & & 20 \\
\hline Chile & 1 & & & & & & & & & & 1 \\
\hline Colombia & 6 & 12 & 4 & 7 & 5 & 3 & 2 & 7 & 9 & 7 & 62 \\
\hline \multicolumn{12}{|l|}{ Costa Rica } \\
\hline \multicolumn{12}{|l|}{ Cuba } \\
\hline Ecuador & & & 1 & & & & & & & & 1 \\
\hline El Salvador & 2 & & & 1 & & & & 1 & & & 4 \\
\hline Guatemala & 2 & 1 & 1 & 3 & 2 & 2 & 4 & 3 & 1 & 1 & 20 \\
\hline Honduras & & & & 1 & & & 1 & & & & 2 \\
\hline México & 3 & 6 & 3 & 5 & 5 & 2 & 2 & 4 & 4 & 2 & 36 \\
\hline \multicolumn{12}{|l|}{ Nicaragua } \\
\hline \multicolumn{12}{|l|}{ Panamá } \\
\hline Paraguay & & 1 & & & & & & 1 & & & 2 \\
\hline Perú & 3 & 7 & 7 & 2 & & & 1 & 1 & 1 & 1 & 23 \\
\hline R. Dominicana & & & & & 1 & 1 & & & & & 2 \\
\hline \multicolumn{12}{|l|}{ Uruguay } \\
\hline Venezuela & & & 3 & 1 & & & & & & & 4 \\
\hline Total & 17 & 29 & 20 & 21 & 15 & 15 & 13 & 21 & 17 & 12 & 180 \\
\hline
\end{tabular}

Fuente: Observatorio Latinoamericano de la Libertad de Prensa (BDN/Infoamérica 2005-2015) 
gistrado para la década en México (36), Perú (23), Brasil (20) y Guatemala (20).

En los diez primeros años del siglo xxI (tabla 8), Colombia pierde el liderazgo (50 casos) y es sobrepasada por la eclosión de violencia en México (69) y el comienzo de la que se ha dado en llamar narcoguerra, cuyas manifestaciones revelan la descomposición del Estado y, como se verá más adelante, una estructura institucional degradada que no solo no combate las agresiones, sino que toma parte en ellas y refuerza el ambiente de impunidad en el que se producen. Entre enero de 2010 y mediados de 2015, el protagonismo de México adquiere una relevancia dramática. Solo en cinco años y medio supera los registros de décadas anteriores, con 73 casos, cuando Colombia aminora significativamente su peso estadístico (14), sobrepasada en la lista negra por Brasil (27) y, muy especialmente, por Honduras (47), donde a las consecuencias del golpe de Estado de 2009 se unen muchos de los factores ambientales e institu- cionales que describen a los sistemas fallidos ${ }^{12}$. La densidad de las agresiones en Honduras es especialmente alarmante, ya que con apenas 8,7 millones de habitantes, catorce veces inferior a la de México, el número de víctimas se eleva a 47 en los últimos cinco años y medio, lo que revela la violencia relativa más alta en los 45 años de este estudio.

El recuento global para el período 1970-2015 recoge 1027 casos documentados, no siempre esclarecidos y argumentados en cuanto a las motivaciones, relación con la libertad de expresión, compromiso ético de la víctima, etc., entre otras razones por la opacidad que ha rodeado a muchos de estos sucesos, la debilitada o nula acción de la justicia y el reinado amplio de la impunidad. Ciertamente, cabe distinguir entre periodistas muertos violentamente en el ejercicio de la profesión de los muertos violentamente por razones no esclarecidas. Por ello, se puede afirmar que no siempre se refleja en los datos estadísticos la causalidad del hecho violento,

12 La expresión de un sistema fallido se advierte en la información que se ofrece sobre la realidad nacional por parte de las organizaciones defensoras de los Derechos Humanos. La web Conexihon/Comunicación para vencer el miedo (http://conexihon.hn) del Comité por la Libre Expresión (C-Libre), que promueve la Libertad de Expresión y el Derecho a la Información en Honduras, publicó, el 30 de junio de 2015, un informe detallado bajo el título: "Narcodiputado' habría ordenado matar a ocho periodistas hondureños". Con ocasión del viaje del papa Francisco a América Latina, en julio de 2015, el Sindicato de Periodistas del Paraguay (SSP) le envió un mensaje en el que hacía referencia a los asesinatos de periodistas en el país y "a la incursión del narcotráfico en la política y en el poder público, proceso que hoy toda la ciudadanía conoce como 'narcopolítica'”. 
pero sí que este se produjo y acabó con la vida de un periodista o provocó su desaparición ${ }^{13}$.
A pesar de la dureza del terrorismo de Estado en el caso de la dictaduras militares, las cifras dramáticas que

Tabla 8

Periodistas muertos y desaparecidos en América Latina (2000-2009)

\begin{tabular}{|c|c|c|c|c|c|c|c|c|c|c|c|}
\hline & 2000 & 2001 & 2002 & 2003 & 2004 & 2005 & 2006 & 2007 & 2008 & 2009 & Total \\
\hline \multicolumn{12}{|l|}{ Argentina } \\
\hline Bolivia & & 1 & & & & & & & 1 & & 2 \\
\hline Brasil & 2 & 4 & 2 & 4 & 2 & 2 & 2 & 2 & 1 & 1 & 22 \\
\hline \multicolumn{12}{|l|}{ Chile } \\
\hline Colombia & 10 & 9 & 11 & 7 & 2 & 3 & 3 & 2 & & 3 & 50 \\
\hline Costa Rica & & 1 & & 1 & & & & & & & 2 \\
\hline \multicolumn{12}{|l|}{ Cuba } \\
\hline Ecuador & & & & & & 1 & 2 & & 1 & & 4 \\
\hline El Salvador & & & & & & & 1 & 1 & & 1 & 3 \\
\hline Guatemala & 1 & 1 & & 2 & & & 2 & 2 & 4 & 2 & 14 \\
\hline Honduras & & & & 1 & & & 1 & 1 & 1 & 3 & 7 \\
\hline México & 5 & 3 & 2 & 3 & 7 & 3 & 12 & 10 & 9 & 15 & 69 \\
\hline Nicaragua & & & & & 2 & 1 & & & & & 3 \\
\hline Panamá & & & & & & & & & 1 & & 1 \\
\hline Paraguay & 1 & 1 & 1 & & 1 & & & 1 & & 2 & 7 \\
\hline Perú & & & & & 2 & & & 1 & & & 3 \\
\hline R. Dominicana & & & & & 1 & & 3 & & 1 & & 5 \\
\hline Uruguay & 1 & & & & & & 1 & & & & 2 \\
\hline Venezuela & & & 1 & & 1 & & 5 & & 1 & 2 & 10 \\
\hline TOTAL & 20 & 20 & 17 & 18 & 18 & 10 & 32 & 20 & 20 & 29 & 204 \\
\hline
\end{tabular}

Fuente: Observatorio Latinoamericano de la Libertad de Prensa (BDN/Infoamérica 2005-2015)

13 Así, en la base de datos de la Fundación para la Libertad de Prensa, acorde con la excelente labor de seguimiento de las agresiones de todo tipo y la impunidad de los delitos, se recoge entre los periodistas asesinados en 1998 a Bernabé Cortés Valderrama, con sentencia condenatoria para sus agresores, del que Javier Darío Restrepo escribe: “Las reseñas periodísticas sobre su asesinato consignaron, como parte de su hoja de vida, que su nombre había figurado en las listas de presuntos destinatarios de dineros del narcotráfico, reveladas ante la justicia de Estados Unidos por el ex contador del cártel de Cali Guillermo Palomari" ("Noticias de alto riesgo", 1999, en Sala de Prensa, año 2, vol. 2, http://www.saladeprensa.org/art31.htm). 
Tabla 9

Periodistas muertos y desaparecidos en América Latina (2010-2015)

\begin{tabular}{|c|c|c|c|c|c|c|c|}
\hline & 2010 & 2011 & 2012 & 2013 & 2014 & $2015^{\star}$ & Total \\
\hline \multicolumn{8}{|l|}{ Argentina } \\
\hline Bolivia & & 1 & & & & & 1 \\
\hline Brasil & 2 & 6 & 6 & 7 & 3 & 3 & 27 \\
\hline \multicolumn{8}{|l|}{ Chile } \\
\hline Colombia & 3 & 1 & 3 & 3 & 2 & 2 & 14 \\
\hline \multicolumn{8}{|l|}{ Costa Rica } \\
\hline \multicolumn{8}{|l|}{ Cuba } \\
\hline Ecuador & 2 & & 1 & 1 & & & 4 \\
\hline El Salvador & & 1 & & & 1 & & 2 \\
\hline Guatemala & 1 & 1 & & 4 & & 3 & 9 \\
\hline Honduras & 12 & 6 & 8 & 3 & 9 & 9 & 47 \\
\hline México & 19 & 13 & 14 & 8 & 9 & 10 & 73 \\
\hline \multicolumn{8}{|l|}{ Nicaragua } \\
\hline Panamá & & 1 & & & & & 1 \\
\hline Paraguay & & 1 & & 2 & 3 & 1 & 7 \\
\hline Perú & & 3 & & 1 & 2 & & 6 \\
\hline R. Dominicana & & 1 & & & 2 & 1 & 4 \\
\hline \multicolumn{8}{|l|}{ Uruguay } \\
\hline Venezuela & & 1 & & & & & 1 \\
\hline TOTAL & 39 & 36 & 32 & 29 & 31 & 29 & 196 \\
\hline
\end{tabular}

* Hasta el 15-10-2015

Fuente: Observatorio Latinoamericano de la Libertad de Prensa (BDN/Infoamérica 2005-2015)

denunciaron la persecución y el crimen en Argentina, Chile, Brasil y otras naciones sudamericanas (Salomone, 1999; Carmona, 1997), han sido desbordadas por el desgobierno y la acción del crimen organizado, cuando no por la connivencia entre expresiones ilegítimas y corruptas de poder, así como por la ineficacia de las instituciones llamadas a la defensa del Estado de derecho (Guerrero, 2010; Gibons y Spratt, 2010). México, con 222 muertes y desapariciones, duplica prácticamente el registro de Argentina (120), casi exclusivamente referido a los años setenta del pasado siglo y, en poco tiempo, ha sobrepasado ampliamente la cifra de Colombia (173). Guatemala (125) se sitúa ligeramente por encima de Argentina, pero no se debe olvidar que la población de este país es casi tres veces superior a la de Guatemala.

La magnitud territorial de América Latina y su gran diversidad describen realidades sociales y políticas que, en términos de libertad de prensa, marcan 
Tabla 10

Periodistas muertos y desaparecidos en América Latina (1970-2015)

\begin{tabular}{lcccccc}
\hline & $1970-$ & $1980-$ & $1990-$ & $2000-$ & $2010-$ & $1970-$ \\
& 1979 & 1989 & 1999 & 2009 & $2015^{*}$ & $2015^{*}$ \\
\hline México & 12 & 32 & 36 & 69 & 73 & 222 \\
Colombia & 6 & 41 & 62 & 50 & 14 & 173 \\
Guatemala & 19 & 63 & 20 & 14 & 9 & 125 \\
Argentina & 115 & 2 & 3 & & & 120 \\
Brasil & 23 & 12 & 20 & 22 & 27 & 104 \\
Honduras & & 4 & 2 & 7 & 47 & 60 \\
Perú & & 24 & 23 & 3 & 6 & 56 \\
El Salvador & & 37 & 4 & 3 & 2 & 46 \\
Chile & 26 & 4 & 1 & & & 31 \\
Paraguay & & & 2 & 7 & 7 & 16 \\
Uruguay & 13 & & & 2 & & 15 \\
Venezuela & & & 4 & 10 & 1 & 15 \\
R. Dominicana & 2 & 1 & 2 & 5 & 4 & 14 \\
Ecuador & & 1 & 1 & 4 & 4 & 10 \\
Nicaragua & 220 & 227 & 180 & 204 & 196 & 1027 \\
Bolivia & & & & 3 & & 8 \\
Costa Rica & 2 & 1 & & 2 & 1 & 6 \\
Panamá & & 1 & & 2 & & 3 \\
Cuba & & & & 1 & 1 & 3 \\
\hline TOTAL & & & & & & \\
\hline & & & & & & \\
\hline
\end{tabular}

* Hasta el 15-10-2015

Fuente: Observatorio Latinoamericano de la Libertad de Prensa (BDN/Infoamérica 2005-2015)

contrastes acusados. No es lo mismo el escenario de los medios en México y Honduras, por ejemplo, que en naciones del Cono Sur como Uruguay y Chile; o, dentro de las naciones centroamericanas, entre Honduras y Costa Rica, por ejemplo. Aun así, la radiografía de conjunto muestra zonas de máxima tensión en Estados en los que las liber- tades públicas están garantizadas en términos constitucionales, pero donde, en la práctica, el ejercicio del periodismo se encuentra sometido a presiones, extorsiones, violencia y descrédito.

En el período de dictaduras militares, las agresiones se dirigieron contra destacados periodistas cuya militancia y pensamiento eran tenidos por 
"subversivos", acción que se mantuvo en las naciones con conflictos guerrilleros, en este caso, por regla general, en zonas del interior y ámbitos rurales. En las últimas décadas, las víctimas aparecen asociadas, en gran medida, a pequeños medios locales y a ámbitos rurales, con un perfil profesional muy precario, ya que en la mayoría de los casos, pertenecen a medios locales, cercanos a la geografía de las narcoguerras. Por eso, cuando se analizan las cifras de los atentados, no siempre cabe homologarlas con los criterios de registro estadístico que se dan en otras zonas del planeta, donde se conocen mejor las causas y los homicidios, y las víctimas están identificadas como profesionales de la información. No obstante, sería ingenuo admitir la

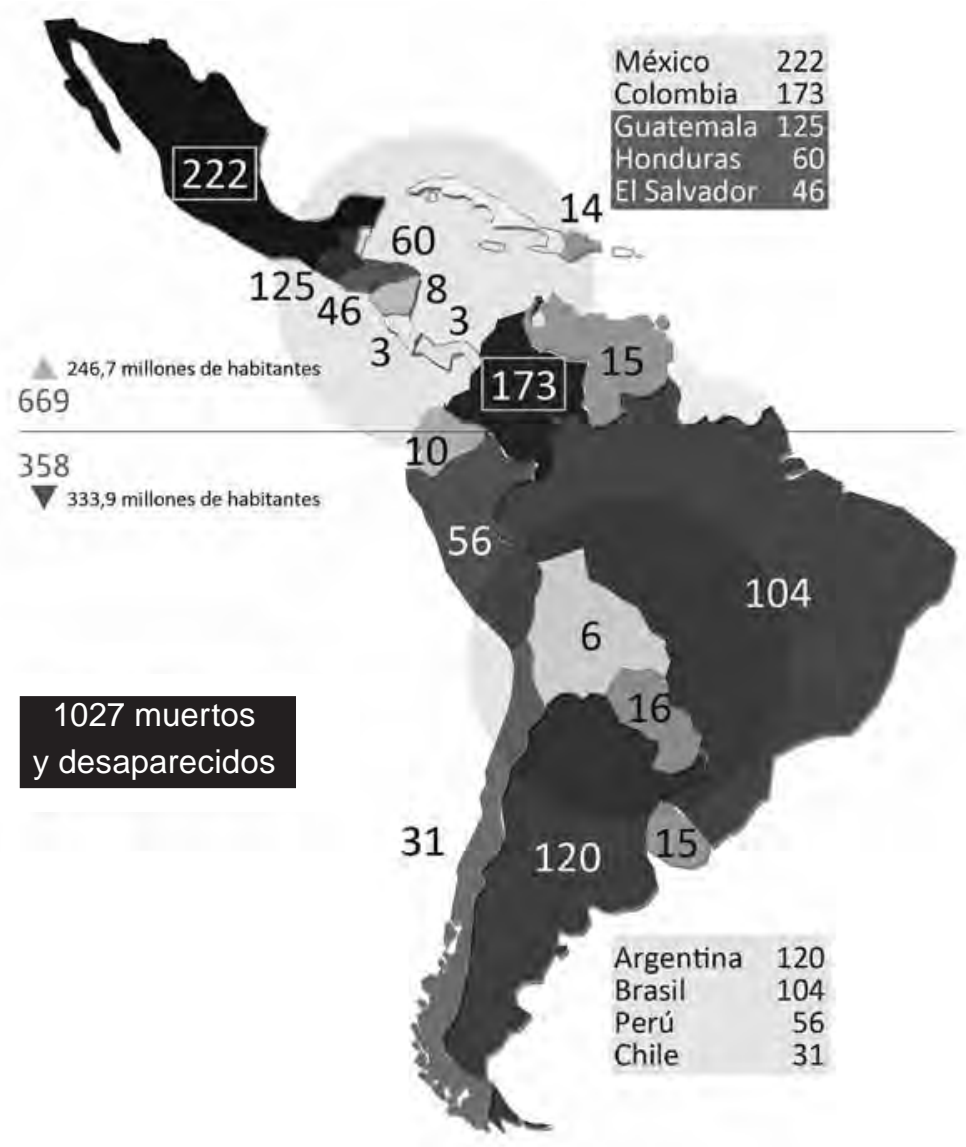

Figura 1. Periodistas asesinados y desaparecidos 1970-2015*

* Hasta el 15 de octubre de 2015 
bondad universal de los periodistas e ignorar cómo en muchos casos de precariedad laboral o simple deriva corrupta, cuando no extremo acoso ambiental, existen vinculaciones con el narcotráfico y el crimen organizado, o negar que algunas víctimas han sido objeto de ajustes de cuentas y de la violencia estructural en entornos críticos. Describir, en términos éticos, las distintas categorías de periodistas es un trabajo que excede al propósito de este artículo.

Cuando se notifica, por parte de las organizaciones profesionales, una alerta sobre una agresión o una muerte, se describen sucintamente los hechos dramáticos del caso -características del acto violento, armas empleadas, amenazas previas, torturas, etc.-, pero no se dan detalles que serían reveladores acerca de las víctimas: grado de formación, dedicación y vínculo profesional, remuneración, pertenencia a organizaciones gremiales... A la vista de muchas de las identidades truncadas por la violencia, cabe formular la hipótesis de que un buen número trabajaba de forma autónoma, percibía bajos o muy bajos salarios cuando no desarrollaba un ejercicio de voluntariado, como en el caso de los comunicadores sociales que animan los medios comunitarios. Esta circunstancia no puede, en ningún caso, devaluar el alcance de estas muertes y desvincularlas de las agresiones a la libertad de prensa. Todos ellos son actos de violencia extrema destinados a silenciar voces críticas y a atemorizar a aquellas otras que se pro- nuncian o pudieran pronunciarse en términos similares.

Aun cuando en América Latina se conoce un enorme despliegue académico en torno a la formación de los periodistas y comunicadores, la vida profesional, en los territorios castigados por la violencia, manifiesta signos de realidad dual, descrita por el contraste entre periodistas de grandes medios, relativamente bien remunerados, $\mathrm{y}$ otros que viven en condiciones muy distintas. La precariedad laboral, la baja autoestima, la desconfianza y el miedo se ceban sobre los que, a la vez, son víctimas de los atentados y aquellos que, por estas circunstancias, resultan más fáciles de seducir por el crimen organizado. La desprotección se acentúa en los medios comunitarios hasta conseguir su marginación o la desaparición. De ahí que, ante sucesos cruentos, los grandes medios, adscritos a una realidad dual, se limiten a dar una breve nota, sin que se advierta una respuesta masiva, colegiada, visible del resto de los profesionales, es decir, un apagón simbólico de su actividad.

\section{Bajo el paraguas de la impunidad}

La impunidad amplia y generalizada que ampara a quienes, por razones muy diversas, hostigan a los periodistas y obstaculizan la libertad de prensa, anima la continuidad de las agresiones, pero también deja ver la naturaleza ética y política de los que están llamados a su defensa y a garantizar el derecho a la información de las au- 
Tabla 11

Índices de impunidad CPJ (2008-2014)

\begin{tabular}{lcccccccc}
\hline & & 2008 & 2009 & 2010 & 2011 & 2012 & 2013 & 2014 \\
\hline México & Ranking | casos & $10 \mid 7$ & $11 \mid 5$ & $\mathbf{9} 9$ & $\mathbf{8} \mid 13$ & $\mathbf{8} \mid 15$ & $\mathbf{7} \mid 15$ & $\mathbf{7} \mid 16$ \\
& Casos/millón habs. & 0.068 & 0.057 & 0.085 & 0.121 & 0.132 & 0.131 & 0.132 \\
\hline Colombia & Ranking | casos & $\mathbf{4} \mid 20$ & $\mathbf{5} \mid 16$ & $\mathbf{5} \mid 13$ & $\mathbf{5} \mid 11$ & $\mathbf{5} \mid \mathbf{8}$ & $\mathbf{5} \mid \mathbf{8}$ & $\mathbf{8} \mid 6$ \\
& Casos/millón habs. & 0.439 & 0.347 & 0.292 & 0.241 & 0.173 & 0.171 & 0.126 \\
\hline \multirow{2}{*}{ Brasil } & Ranking | casos & $>13$ & $13 \mid 5$ & $>12$ & $12 \mid 5$ & $11 \mid 5$ & $10 \mid 9$ & $11 \mid 9$ \\
& Casos/millón habs. & & 0.026 & & 0.026 & 0.026 & 0.046 & 0.045 \\
\hline
\end{tabular}

Fuente: CPJ, Global Impunity Index (2008-2014)

Elaboración propia

diencias (Unesco, 2009). Aunque es difícil de verificar, cabe resaltar la lógica de la hipótesis que sostiene que las agresiones a los periodistas se amparan precisamente en la impunidad ${ }^{14}$.

En México, según Article 19 (2015), la ineficacia alcanza a las instancias creadas para atajar la quiebra de la li- bertad de prensa y evitar la catástrofe humanitaria derivada de los continuos atentados. Esa ineficacia es patente tanto en la Fiscalía Especial para la Atención de Delitos cometidos en contra de la Libertad de Expresión (FEADLE) como en la Comisión Nacional de Derechos Humanos (CNHD) ${ }^{15}$.

14 Se trata de un problema común a otros escenarios de violencia contra los periodistas. El Committee to Protect Journalists (CPJ) puso de manifiesto, en 2004, que durante los quince años anteriores cerca del $85 \%$ de los responsables de asesinatos de periodistas no fueron investigados ni enjuiciados. En aquellos casos en los que los asesinatos fueron investigados y se produjeron sentencias, solo el $7 \%$ de los autores intelectuales fueron juzgados.

15 En 2014, Juan Carlos Romero Puga pedía el cierre de la Comisión Nacional de Derechos Humanos de México - "No a la continuidad en la CNDH", en la revista Letras Libres (http:// www.letraslibres.com/blogs/otra-vez/no-la-continuidad-en-la-cndh) [Consultado: 10-82015] - y añadía: “A cada nuevo crimen conocido, su área de comunicación social anuncia el inicio de una investigación por parte de su personal. Sin embargo, sus registros están llenos de errores y se advierte una total falta de consistencia en los criterios empleados sobre la identificación de periodistas asesinados en razón de su trabajo. (...) Tal y como funciona ahora, a nadie conviene la continuidad del Programa de Agravios a Periodistas y Defensores Civiles de Derechos Humanos: burócratas sin conocimiento del tema, que no entienden en qué consiste el ejercicio periodístico, cuyas investigaciones se reducen a recortes de prensa, e incapaces de verificar los datos o el estatus de casos en sus manos, convirtiendo a las personas en muescas en un pizarrón, falsificación de un trabajo serio en el tema que luego presentan a los medios como datos fiables". 
La impunidad podría alcanzar al $89 \%$ de los casos en México, según la Oficina del Alto Comisariado de las Naciones Unidas en este país, a pesar de la existencia de una Fiscalía especializada y todo un aparato de retórica legal tan amplio como ineficaz. Esta falta de diligencia en la persecución del crimen no es nueva y, con frecuencia, se implica en el origen de las agresiones a policías, políticos y funcionarios, lo que hace mucho más difícil la acción de la justicia y favorece el imperio de la impunidad.

Según el estudio Estado de silencio (Article 19, 2015, p. 22), de las 326 agresiones documentadas en México en 2014 se conocía la autoría de 240, encabezada en 156 casos por funcionarios, en 52 por particulares y solo en 8 por el crimen organizado, que podría estar presente en gran parte de los 86 casos de autoría ignorada o no verificada.

En México, existe una doble fachada de la realidad. Una, de naturaleza retórica, declarativa, que alardea desde las instituciones gubernamentales de la adopción continua de medidas, y otra que habla de ineficacia, falta de voluntad política e incapacidad para resolver el problema. Hay violencia extrema en las acciones de los cárteles, pero la violencia contra los periodistas tiene otros protagonismos que alcanzan a las policías municipales, estatales y federales, e incluso al Ejército ${ }^{16}$.

Aunque, ante la mayoría de los homicidios de periodistas, estos se atribuyen al crimen organizado, un estudio del canadiense PEN Internacional y la Universidad de Toronto afirma que dos de cada tres crímenes son obra de agentes del Estado (Gibons y Sppatt, 2011, p. 20), y afectarían fundamentalmente a aquellos periodistas que indagan y exponen la corrupción gubernamental y sus lazos con el narcotráfico. Según CPJ, entre 2006 y 2015, el 69 \% de los casos identificados se corresponde con crímenes de los cárteles de la droga y, al menos, el $22 \%$ es atribuido a los gobiernos, a las fuerzas policiales y a los militares.

La inacción de la justicia y la impunidad no son exclusivas de la realidad mexicana. La Fundación para la Libertad de Prensa (FLIP, 2015b) denuncia en Colombia los casos de homicidios

16 En una carta entregada al presidente y otras autoridades de la nación, en mayo de 2014, suscrita por las organizaciones periodísticas de México, se ponía de manifiesto la desconfianza en la eficacia institucional en la persecución del delito: “Tenemos claro que la Fiscalía Especial de Atención a Delitos contra la Libertad de Expresión de la PGR no ha mostrado la eficacia necesaria (...) El Mecanismo de Protección de Secretaría de Gobernación no ha podido actuar conforme a la ley que le dio origen. (...) Por este clima de agresiones y claros síntomas de ineficacia del Estado, también siguen creciendo la autocensura y las zonas del silencio impuestas con violencia". 
que, una vez pasados veinte años, prescriben, y advierte de que, en 2014, de las 338 investigaciones de amenazas, solo una se sustanció en resolución condenatoria ${ }^{17}$.

Las condenas por parte de la justicia son hechos aislados que, en la mayoría de los casos, alcanzan a los autores materiales de los asesinatos, pero no a los instigadores de los crímenes. CPJ calificó de hecho histórico la condena en Colombia, en 2015, después de tres años de demoras, el asesinato de testigos y fallos judiciales controvertidos, del autor intelectual del atentado contra el periodista Orlando Sierra Hernández, subdirector del diario La Patria de Manizales, ocurrido en 2002 (CPJ, s. f.). Para la FLIP, fue la primera vez que en este país todos los involucrados en el crimen fueron condenados ${ }^{18}$.

La situación es probablemente más grave en algunas naciones de Centroamérica (Green, 2015; OEA-CI-
DH, 2013), especialmente en Honduras, donde, después del golpe de 2009, se han desfigurado las huellas del Estado de derecho. Los datos del Comisionado Nacional de los Derechos Humanos revelan que, desde finales de 2003, se contabilizan 54 periodistas asesinados, pero solo 3 de ellos, el 5,9\%, han sido resueltos con una sentencia condenatoria. El 94,1 \% permanece en la impunidad.

Como en México, las autoridades dicen asumir y respetar los compromisos internacionales, incluida la más reciente resolución de Naciones Unidas $^{19}$, pero en la práctica parecen carecer de voluntad política para ofrecer respuestas eficaces y acordes con criterios básicos de cultura democrática.

\section{Por último, y no es todo...}

La impunidad, estrechamente vinculada a la inacción de la justicia, a la incapacidad y a la corrupción de los

17 Según la Fundación, que atribuye a la Fiscalía la inoperancia de la justicia, cinco muertes de periodistas ocurridas en los últimos años en Colombia podrían haber sido evitadas, ya que en todos los casos las autoridades locales y la policía conocían las amenazas que pesaban sobre ellos. En Colombia, "el Estado no ha pecado por acción, sino por omisión" (Lozano y González, 2004).

18 Recientemente se ha revelado el espionaje al que durante sesenta años fueron sometidos los periodistas colombianos por parte de los aparatos del Estado (FLIP, 2015b).

19 La resolución 2222 de Naciones Unidas, aprobada por unanimidad el 27 de mayo de 2015, condena enérgicamente la impunidad, porque "puede contribuir a que estos actos se repitan", y destaca que los Estados "tienen la responsabilidad de cumplir las obligaciones pertinentes impuestas por el derecho internacional de poner fin a la impunidad y procesar a los responsables de cometer violaciones graves del derecho internacional humanitario". 
aparatos de poder, aparece como manifestación central de la quiebra de la práctica democrática que se ha analizado, de la que solo se recoge una faceta muy limitada del problema. Es preciso profundizar en aquellas situaciones donde a la condición de periodista se unen otros factores de discriminación, exclusión y riesgo.

Los colectivos de mujeres periodistas de México denuncian los peligros que corren, ya que al castigo por su actividad profesional se une la crisis de feminicidio que aparece como otra de las grandes debilidades democráticas del país (CIMAC, 2012).

También se advierten problemas específicos en sectores de la sociedad que siguen castigados por la exclusión y la pobreza, caso de los colectivos indígenas, en torno a los cuales surgen muchas de las iniciativas de medios comunitarios.

Reporteros Sin Fronteras analizó este problema en el departamento del Cauca, en Colombia, y los efectos colaterales de las luchas armadas y el narcotráfico sobre la vida y expectativas de estas poblaciones, con amenazas procedentes tanto del Ejército, que los tiene por "simpatizantes de la guerrilla", como por parte de los grupos armados, que los acusan de ser "colaboradores del Estado", al tiempo que grupos radicales practican sobre ellos mecanismos de "limpieza social" (RSF, 2012).

Situación no muy diferente a la que se conoce en México y en algunas naciones centroamericanas, donde estas poblaciones son víctimas y eslabón del narcotráfico, a la vez que padecen la desprotección de las políticas públicas (AMARC, 2009).

Muchos medios comunitarios han sido destruidos o cerrados, las poblaciones se han desplazado y son numerosos los comunicadores y periodistas que buscan refugio lejos de su tierra.

\section{Referencias}

Acosta Urquidi, M. (Coord.). (2012). La impunidad crónica en México: una aproximación desde los Derechos Humanos. México, D. F.: Comisión de Derechos Humanos del Distrito Federal (CDHDF).

AMARC - Asociación Mundial de Radios Comunitarias (2009). Radios comunitarias y contexto de conflicto en México. México, D. F.: AMARC-México.

Article 19 (2015). Estado de silencio: Informe 2014 sobre violencia contra la prensa. México, D. F.: Article 19 México.

Article 19 et al. (2008). Press Freedom in Mexico: The shadow of impunity and violence. Copenhague: International Media Suport.

Blaustein, E., y Zubieta, M. (1998). Decíamos ayer. La prensa argentina bajo el Proceso. Buenos Aires: Colihue.

Cardona, J. (2009). Días de memoria. Bogotá: Aguilar.

Carmona, E. (1997). Morir es la noticia. Santiago: E. Carmona Ed.

Cencos - Centro Nacional de Comunicación Social. (2012). ¿Por qué tanto 
silencio? Daño reiterado a la libertad de expresión en México 2012. México, D. F.: Centro Nacional de Comunicación Social.

Cimac. (2012). Violencia contra mujeres periodistas. México 2010-2011. México, D. F.: Cimac/Fundación Heinrich Böll.

CPJ. (s. f.). Historic conviction of mastermind in Colombian journalist's murder (25-06-2015). Recuperado de https://cpj.org/2015/06/historic-conviction-of-mastermind-in-colombian-jou.php

Elías, J. (2005). Maten al cartero: posdata del asedio a la prensa durante las dictaduras militares del Cono Sur. Buenos Aires: CADAL.

FLIP - Fundación para la Libertad de Prensa (2015a). 15 años de protección de periodistas en Colombia: esquivando la violenciasin justicia. Bogotá:Fundación para la Libertad de Prensa.

FLIP - Fundación para la Libertad de Prensa (2015b). 60 años de espionaje a periodistas en Colombia. Bogotá: Fundación para la Libertad de Prensa.

FLIP - Fundación para la Libertad de Prensa (2013). De las balas a los expedientes. Informes sobre el estado de la libertad de prensa en Colombia en 2012. Bogotá: Fundación para la Libertad de Prensa.

FLIP - Fundación para la Libertad de Prensa (2002-2014). Informes anuales sobre el estado de la libertad de prensa en Colombia, 2002-2014. Bogotá: Fundación para la Libertad de Prensa.
Gibons, C., y Spratt, B. (2011). Corruption, impunity, silence: The war on Mexico's journalists. Toronto: PEN Canadá/Toronto University.

Green, W. J. (2015). A history of political murder in Latin America: Killing the messengers of change. Nueva York: State University of New York Press/ Suny Press.

Guerrero, A. (2010). País lejano y silenciado: autocensura y prácticas periodísticas en el periodismo regional. Bogotá: Fundación para la Libertad de Prensa/ Medios para la Paz. Recuperado de http://flip.org.co/autocensura/ INFODIAGNOSTICO.pdf

Lozano, J., y González, J. (2004). La censura del fuego. Bogotá: Intermedio.

Moncada Ochoa, C. (2012). Oficio de muerte. Periodistas asesinados en el país de la impunidad. México, D. F.: Grijalbo.

Nuestra Aparente Rendición (20 de julio de 2013). Veracruz, el miedo que silencia. Recuperado de http://nuestraaparenterendicion.com/index. php/blogs-nar/red-de-periodistasde-a-pie/item/1870-veracruz-el-miedo-que-silencia

OEA-CIDH. (2008). Estudio especial sobre asesinato de periodistas. Washington: OEA. Relatoría Especial para la Libertad de Expresión.

OEA-CIDH. (2013). Violencia contra periodistas y trabajadores de medios. Washington: OEA. Relatoría Especial para la Libertad de Expresión. 
Oesterheld, G., Sajón, E., y Suárez, E. (1998). Los periodistas desaparecidos: las voces que necesitaba silenciar la dictadura. Buenos Aires: Norma.

Robinson, L. et. al. (2009). Colombia: The war against journalists. Nieman Reports, 55(1). Cambridge, MA: Nieman Foundation for Journalism/ Harvard University.

RSF - Reporteros Sin Fronteras. (2012). Las ondas contra las balas: las radios indígenas del Cauca. Bogotá: Reporteros Sin Fronteras. Recuperado de http://es.rsf. org/IMG/pdf/cauca-informe.pdf

Salomone, F. (1999). Maten al mensajero. Periodistas asesinados y desaparecidos desde Mariano Moreno hasta José Luis Cabezas. Buenos Aires: Sudamericana.

Schindel, E. (2012). La desaparición a diario: sociedad, prensa y dictadura. Villa María, Argentina: Eduvim.

Unesco. (2009). Press freedom safety of journalists and impunity. Annual Conference on the occasion of World Press Freedom Day. París: Unesco.

\section{Bibliografía}

Altolaguirre, M. (1994). Periodismo, derechos humanos y control del poder político en Centroamérica. San José de Costa Rica:Instituto Interamericano de Derechos Humanos.

Article 19 y Fundar. (2015). Libertad de expresión en venta: acceso a información y censura indirecta en publicidad oficial. México, D. F.: Article 19 - México.
Ball, P. D. et al. (1999). Violencia institucional en Guatemala, 1960 a 1996: una reflexión cuantitativa. Washington DC: AAAS.

Bonilla Vélez, J. I., y Tamayo Gómez, C. (2013). Medios, periodismo y conflicto armado. La agenda investigativa sobre la cobertura informativa del conflicto armado en Colombia, 2002-2012. Medellín y Cartagena: FNPI.

Camarillo Carbajal, M. T. (1985). La represión a la prensa en América Latina: hemerografía, 1978-1982. México, D. F.: UNAM-IIB-HN.

Desco - Centro de Estudios y Promoción del Desarrollo. (1989). Violencia política en Perú 1980-1988. Lima: Centro de Estudios y Promoción del Desarrollo.

Echechume, H. (1997). Periodistas bajo fuego: los ataques a la libertad de prensa. Buenos Aires: Catálogos.

Erlick, J. C. (2004). Disappeared: a journalist silenced the Irma Flaquer story. Berkeley, CA: Seal Press.

FGCI - Fundación Guillermo Cano Isaza. (2006). Apuntes a dos décadas de periodismo bajo presión. Bogotá: Fundación Guillermo Cano Isaza. Recuperado de http://goo.gl/rkxM9

Giraldo, D., Roldán, I., y Flórez, M. (2003). Periodistas, guerra y terrorismo. Bogotá: Planeta.

Gómez Gallardo, P., y Flores, B. (2013). Las víctimas tienen derecho a saber: seis casos de ataques a periodistas sin resolver. México, D. F.: Freedom House. 
Guerrero, M. A., y Márquez Ramírez, M. (Eds.). (2014), Media systems and communication policies in Latin America. Basingstoke, UK: Palgrave Macmillan.

IIDH - Instituto Interamericano de Derechos Humanos (2005). El estado de la libertad de expresión en Centroamérica, México y República Dominicana. San José deCostaRica:InstitutoInteramericano de Derechos Humanos.

IPYS - Instituto de Prensa y Sociedad. (2002). Prensa y militares: treinta años de relaciones tormentosas en el Perú. Lima: Instituto de Prensa y Sociedad.

Koonings, K., y Kruijt, D. (2002). Las sociedades del miedo. El legado de la guerra civil, la violencia y el terror en América Latina. Salamanca: Universidad de Salamanca.

Kushnir, B. de (2004). Cães de guarda: jornalistas e censores. São Paulo: Boitempo.

Manrique, M., y González, C. (2008). La palabra desarmada: futuro del periodismo en Colombia. Bogotá: Medios para la Paz.

Moncada Ochoa, C. (1991). Del México violento: periodistas asesinados. México, D. F.: Edamex.

Quiroga Santa Cruz, M. (1982). Juicio a la dictadura: Bolivia recupera la palabra. La Paz: MEP.

Rey, G., y Bonilla, J. (2004). Calidad informativa y cubrimiento del conflicto. Estándares de calidad periodística en el cubrimiento del conflicto armado en Colombia. Bogotá: Proyecto Antonio Nariño. Recuperado de http://goo.gl/bBII2
Rincón, O., y Ruiz, M. (2002). Bajo todos los fuegos: los periodistas en el conflicto colombiano. Bogotá: Proyecto Antonio Nariño.

Ríos, V. (2012). El asesinato de periodistas y alcalde en México y su relación con el crimen organizado. En J. A. Aguilar (Coord.), Las bases sociales del crimen organizado $y$ la violencia en México, pp. 275-308. México, D. F.: CIES.

Ronderos, M., Ruiz, M., y Escamilla, Ó. (2003). Manual de autoprotección para periodistas en el conflicto colombiano. Bogotá: Fundación para la Libertad de Prensa. Recuperado de http:// www.centrodepublicaciones.com/ upload/files/libro_82_543.pdf

Spindler, W. (2007). Los periodistas colombianos frente al desplazamiento forzado. En J. Bernabé Fraguas (Ed.), Periodismo preventivo. Madrid: Los Libros de la Catarata.

Trotti, R. (1999). Impunity no more: unpunished crimes against journalists. Miami: Inter American Press Association.

Ugaz Sánchez-Moreno, J. C. (1999). Prensa juzgada: treinta años de juicios a periodistas peruanos (1969-1999). Lima: UPC/IPYS/Freedom Forum.

UTPBA - Unión de Trabajadores de Prensa de Buenos Aires (1987). Con vida los queremos: periodistas desaparecidos. Las voces que necesitaba silenciar la dictadura. Buenos Aires: Unión de Trabajadores de Prensa de Buenos Aires. 
UTPBA - Unión de Trabajadores de Prensa de Buenos Aires (1999). Informe regional América Latina: más de 500 periodistas asesinados en las últimas dos décadas. Buenos Aires: Unión de Trabajadores de Prensa de Buenos Aires.
VV. AA. (2002). The war against journalists. Nieman Reports, 55-1. Cambridge, MA: Harvard University.

Woodhull, N. J., y Snyder, R. W. (Eds.). (1998). Journalists in Peril. New Brunswick, NJ: Transaction Pub. 